\title{
Analysis of Slab-column Connections in CFT sections without continuity of the tube
}

\author{
A. Albareda-Valls ${ }^{a *}$, C. Milan ${ }^{a}$, J. Maristany Carreras $^{a}$ and D. Garcia Carrera ${ }^{a}$ \\ ${ }^{a}$ Dep. Technology in Architecture, Universitat Politècnica de Catalunya, Spain \\ *corresponding author, e-mail address: albert.albareda@upc.edu
}

\begin{abstract}
When dealing with concrete-filled tube columns and RC slabs, it is usual to interrupt steel tubes in slab-column connections if the column is mainly compressed. Contractors do prefer to solve these connections with independent tubes, although inner reinforcements may be continuous through the slab. In these cases, both tubes from the upper and lower levels do have base plate connections, with a set of anchor bolts. This procedure saves a lot of time of global works, by making everything easier at the same time, as tubular profiles do not intersect the formwork.

However, this reasonable design for slab-column joints suggest at least some questions about the strength of the concrete at the area of connection, where the tube has been interrupted. On the one hand, the load is transferred through concrete in the slab thickness, since there is no continuity of the tube; on the other hand, concrete at that point becomes triaxially confined due to the restriction to lateral deformation.

This study analyses the validity of this connection method and the differences observed depending on the relative location of the column (corner, façade-lateral-or central pillars). Needless to say that the relative location of the column leads to different confinement patterns in concrete.
\end{abstract}

Keywords: Concrete-filled tubes; slab-column connections; confinement effect.

\section{Introduction}

When dealing with concrete-filled tube columns, slab-column connections may become sensitive points for many constructive reasons. The difficulties related with the discontinuity of the formwork and the different phases of concreting, lead to think about possible alternatives to the continuity of the tube.

This is exactly the case of compressed columns with low bending moment ratios. Columns under this assumption transfer the compressive load from one tube to the other through the slab, by using a base plate bolted connection. In this case, the entire load coming from the tube becomes distributed over the slab, and it is concentrated again on the tube below. The bolts are no necessarily preloaded, since these typology of columns are mostly subjected to compression.

Slab-column tubuluar connections without continuity of the tube guarantee the continuity of reinforcements (Fig. 1).
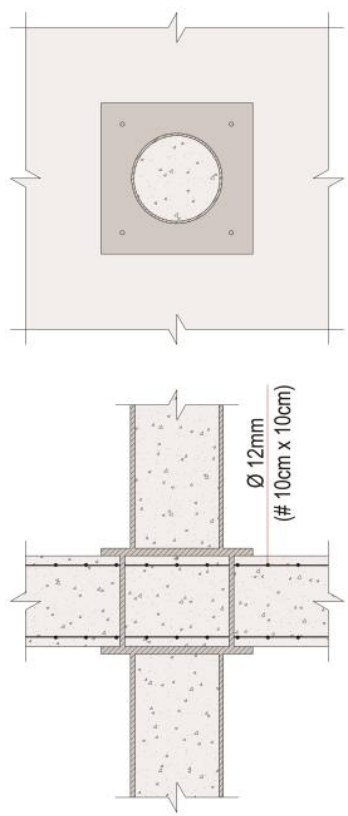

Fig. 1. Slab-column connections without continuity of the tube. 


\section{Hypothesis}

The starting hypothesis of this study is that concrete enclosed within the thickness of the RC slab (Fig. 1) transfers the load from upper tube to the one below, by becoming partially or fully confined, so that the compressive strength may be clearly enhanced.

This phenomenon leads to wonder if this enclosed concrete becomes capable enough of transferring faithfully the load of the pillar. The assumption of axisymmetry in the $\mathrm{X}$ and $\mathrm{Y}$ axes in this case is very important in order to provide effective confinement effect. In this way, the continuity may be totally guaranteed despite the interruption of the tube.

This assumption is different depending on the relative location of the column in the slab, so that a pillar on the corner has very different boundary conditions than a pillar in the middle.

\section{FEM Model}

A full continuum model has been carried out (Fig. 2), by considering the full slab-column connection with axisymmetry conditions in the two axes. The model has been done by Abaqus software, 6.13 edition, with complex material constitutive models and full integration.

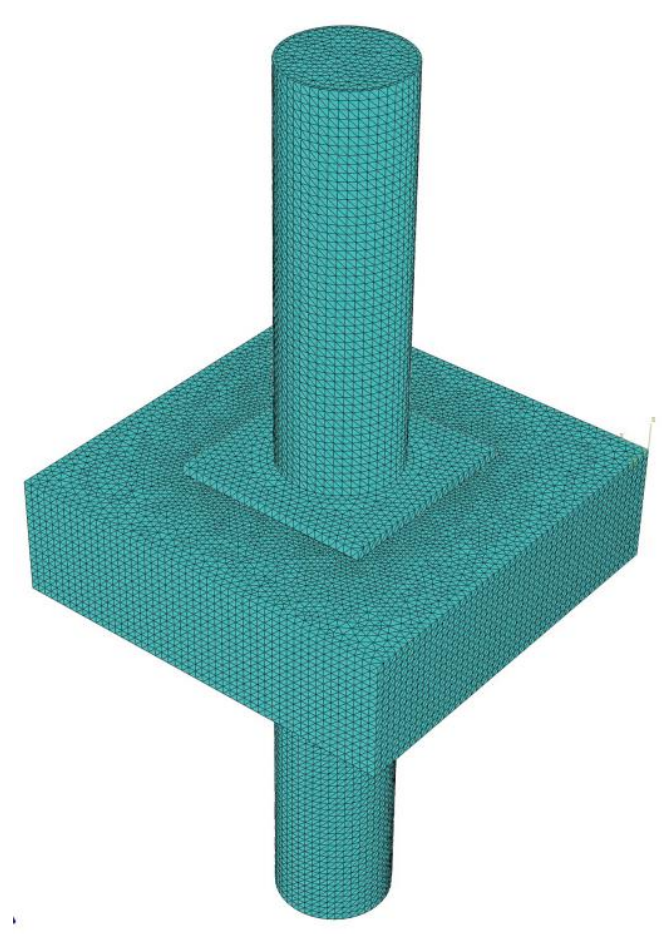

Fig. 2. View of the continuum model used.

\subsection{Mesh and boundary conditions}

A thetrahedral mesh has been chosen for the model in order to fit all different geometries involved. Solid elements have been used for steel and concrete, while "wire" elements have been used for reinforcements. While the lower face of the tube has been encasted, the upper face at the top has been restricted against rotation only.

The load has been applied uniformly to the upper face, through a ramped displacement until reaching the ultimate load.

\subsection{Material models}

The constitutive models for both steel and concrete which has been used in this analysis were calibrated in other occasions by the same authors [1], by taking plasticity criteria into account for both materials. For steel, an elasticplastic model with isotropic plasticity has been implemented, while the CDP model (Concrete Damage Plasticity) has been used for concrete, being sensitive to hydrostatic pressure [2-4].

\section{Numerical analysis}

\subsection{Cases of study}

Three different configurations have been chosen, depending on the relative location of the column, in order to evaluate the efficiency of these simple connections: central, lateral and corner connections, (Fig. 3). While in central pillars, the continuity of the slab guarantees a reliable confinement effect over the enclosed concrete, in corner pillars this may be not clear.

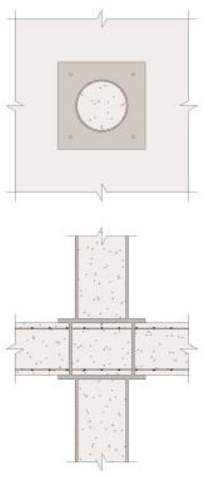

a) Central
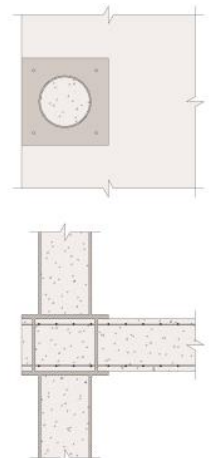

b) Lateral
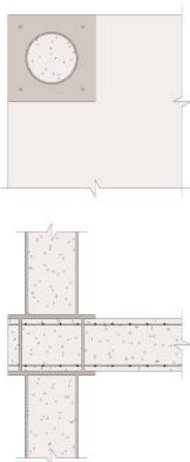

c) Corner
Fig. 3. Slab-column connections without continuity of the tube.

The continuity of the slab in the $\mathrm{X}$ and $\mathrm{Y}$ axes is evaluated as an importany factor in the mechanical response of the joint. Of course the 
thickness of the slab and the base plate are also decisive, but this will require further numerical campaigns in the future.

Analysed tube are $1000 \mathrm{~mm}$ high by each side, and the enclosed slab is $300 \mathrm{~mm}$ thick, with a minimum reinforcement of ø12 in two meshes of $10 \times 10 \mathrm{cms}$ (upper and lower) to reproduce usual dimensions in this typology. Specimens have the following mechanical and geometrical features (Table 1):

Table 1. List of analysed specimens.

\begin{tabular}{llccc}
\hline Specimen & D $_{\text {out }}$ & $\mathbf{t}$ & $\mathbf{f}_{\text {ck }}$ & $\mathbf{f}_{\mathbf{y k}}$ \\
\hline CENTRAL & 300 & 8 & 25 & 275 \\
LATERAL & 300 & 8 & 25 & 275 \\
CORNER & 300 & 8 & 25 & 275 \\
\hline \multicolumn{5}{c}{ Dimensions in mm and strengths in $\mathrm{MPa}$}
\end{tabular}

The connection plate has been considered of $25 \mathrm{~mm}$ thickness, 500x500 mm width, in order to be enough rigid to transfer stresses, and connected with 4 bolts at the edges.

\section{Analysis of results}

\subsection{Transference of load}

As it can be derived from results, there is a faithful transference of load through the RC slab. This transference is enough reliable to allow the interruption of the tube in all cases, despite there is a slight difference in the ultimate load depending on the relative location of the pillar (Fig. 4).

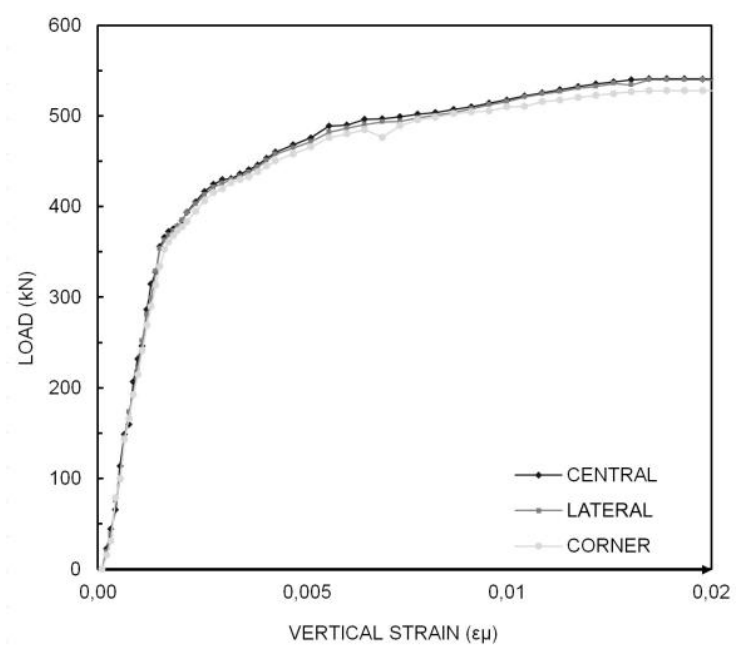

Fig. 4. Load-Strain obtained curves.

The ultimate compressive loads which have been obtained in the numerical analysis are summarized in Table 2, for central, corner and lateral cases. The decrement of compressive capacity is significant in case of the corner specimen, up to a $9,75 \%$ less than the central one, by using the exact solution based on a 4 bolt connection and one base plate by each side.

Table 2. Ultimate load of analysed specimens.

\begin{tabular}{lc}
\hline Specimen & $\mathbf{N}_{\text {pl.Rd }}$ \\
\hline CENTRAL & $541,20 \mathrm{kN}$ \\
LATERAL & $540,00 \mathrm{kN}$ \\
CORNER & $527,90 \mathrm{kN}$ \\
\hline
\end{tabular}

\subsection{Effect of confinement effect in concrete}

It becomes evident, derived from numerical results, that enclosed concrete between the two base plates is subjected to a confinement effect in the three cases, with different patterns. In Figures 5 and 6 below, it can be seen how confinement effect (stresses over $25 \mathrm{MPa}$, in grey) appears later in a) (central pillar) rather than c) (corner pillar). This is caused by the amount of available area of concrete to distribute compressive stresses below the tube, since in case of corner connection this area is significantly lower.

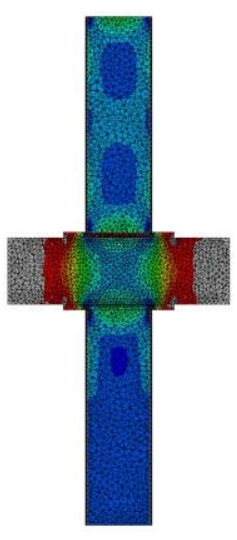

a) Central

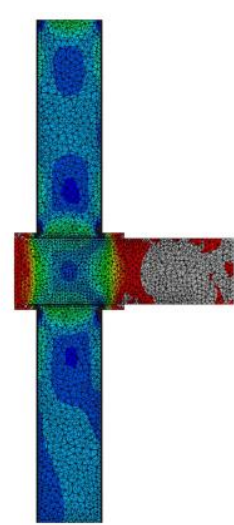

b) Lateral

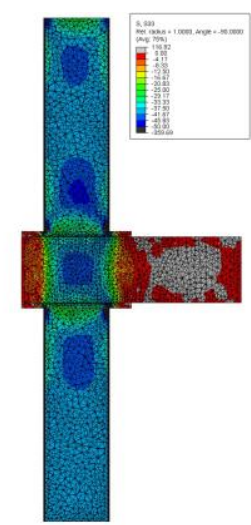

c) Corner Fig. 5. Vertical stress S33, at strains of 0.005 .

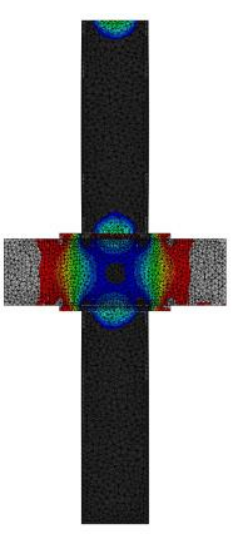

a)Central

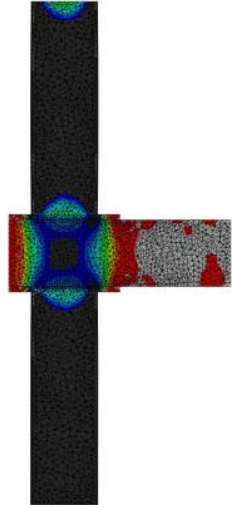

b) Lateral

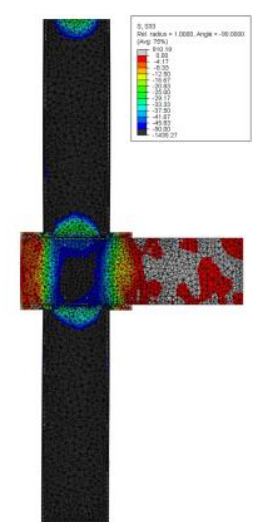

c) Corner
Fig. 6. Vertical stress S33, at strains of 0.01 . 
In order to analyze the capacity of transferring load, it is significant to take into account the pattern of confinement effect; it is directly related with lateral stresses S11 and S22 that appear in the enclosed concrete of the joint (Fig. 7). Once we know the magnitude of these lateral stresses, it is possible to calculate the ultimate confined strength of that enclosed concrete.
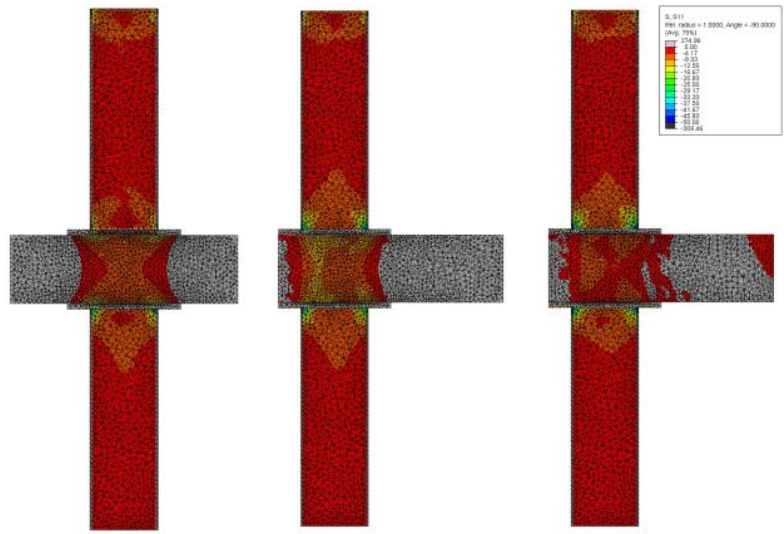

a) Central

b) Lateral

c) Corner

Fig. 7. Lateral stress S11, at strains of 0.005 .
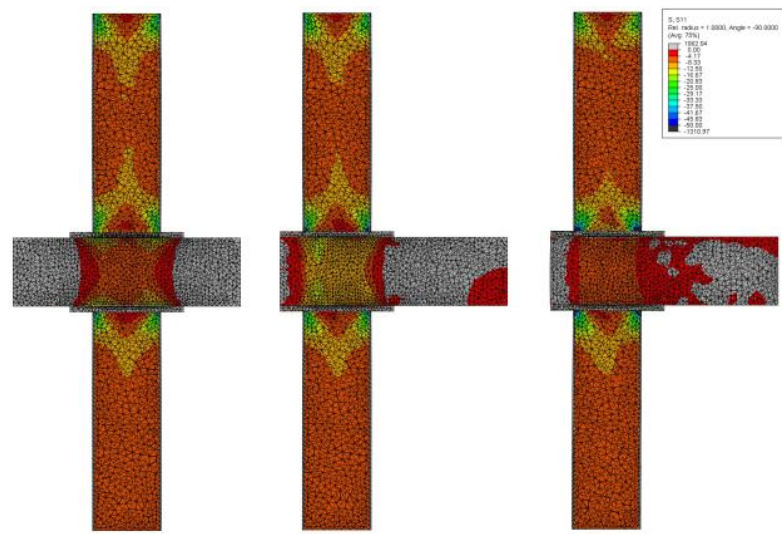
a) Central
b) Lateral
c) Corner

Fig. 8. Lateral stress S11, at strains of 0.01 .

At ultimate strains of 0.01 , lateral stresses $\mathrm{S} 11$ in concrete reach from $8 \mathrm{MPa}$ (Central) to $12 \mathrm{MPa}$ (Lateral). By using the Richart's expression [5] to calculate the confined strength of concrete depending on lateral pressure (Eq. $1)$ :

$$
f c c=f c+m p
$$

The following values are obtained for the maximum confined strength of concrete in each case (Table 3):

Table 3. Confined strength for each case

\begin{tabular}{lcccc}
\hline Specimen & $\mathbf{f}_{\mathbf{c}}$ & $\mathbf{m}$ & $\mathbf{p}$ & $\mathbf{f}_{\mathbf{c c}}$ \\
\hline CENTRAL & 25 & 4.2 & 10 & 67.0 \\
LATERAL & 25 & 4.2 & 12 & 75.4 \\
CORNER & 25 & 4.2 & 8 & 58.6 \\
\hline \multicolumn{5}{c}{ Strengths and pressure in $\mathrm{MPa}$}
\end{tabular}

Thus, the reduction detected in Table 2 of the compressive capacity in transferring the load depending on the three cases, it is mainly not due to the variation of confinement effect, but to the available area to distribute stresses below the plate. Figures 9 and 10 show a horizontal crossection of the slab, with vertical confined stresses.

In case c) (corner), the available volume of concrete to distribute stresses is significantly lower than in case a) (central). Besides, stresses in the latter generate a uniform spherical pattern through the slab thickness which leads to a later appearance of confinement effect.

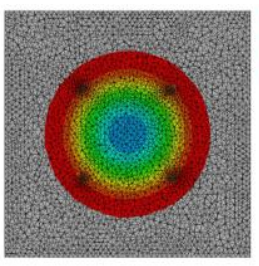

a) Central

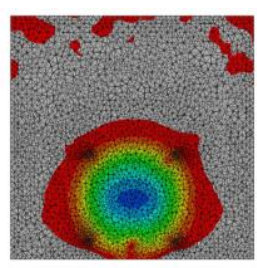

b) Lateral

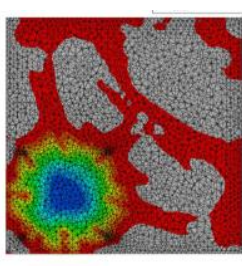

c) Corner Fig. 9. Vertical stress S33, at strain of 0.005 .

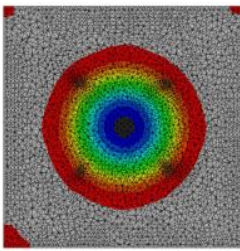

b) Central

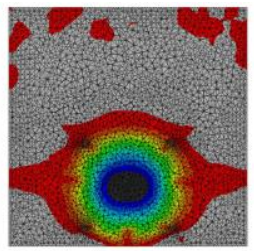

b) Lateral

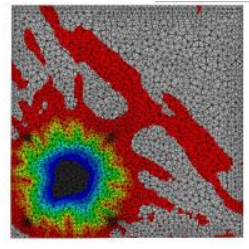

c) Corner Fig. 10. Vertical stress S33, at strains of 0.01 .

Contrarily to the first assumptions in the beginning, confinement effect is not severly influenced by the relative position of the column. The fact of having continuity of the slab in the $\mathrm{X}$ and $Y$ axes does not have a crucial relationship with lateral confinement, but it has in terms of loading stages. Confinement effect in the slab thickness at the corner (c) appears earlier than in the central connection (a), due to the reduction of available concrete volume to distribute the compressive load. 
Since upper and lower base plates of both tubes are located against concrete at both sides of the slab and under compression, the friction forces between both materials becomes significant [6]. This is the reason why concrete tends to dissipate the load through a natural arch effect (see Fig. 11), independently from the continuity of the slab.

Concrete tends to expand laterally when it is subjected to high levels of compression, like in this case [7]; however, this lateral expansion is not possible here due to the proximity between the plates, that restricts lateral deformation through friction forces at the interface.

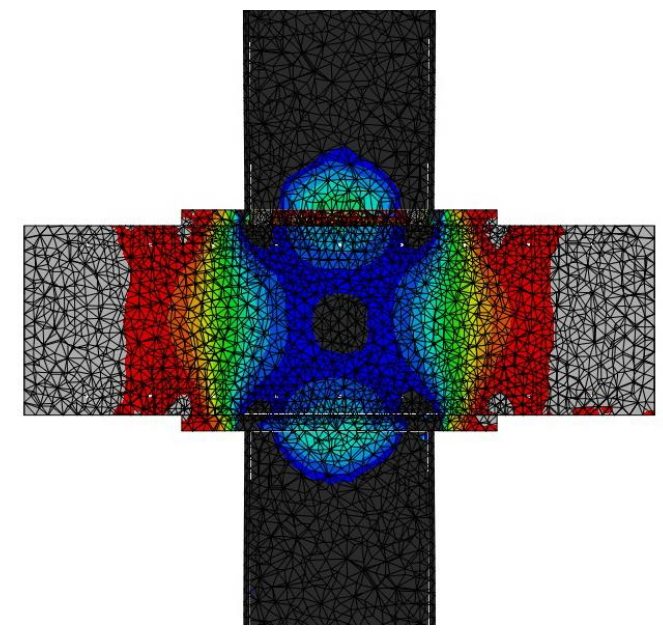

Fig. 11. Natural arch effect between the plates.

A natural arch-effect can be clearly detected in Fig. 11 between the edges of the tube, and it is the main reason why confinement effect appears in a similar way to all different cases. Confinement is provided by the self distribution of stresses between the base plates, thanks to the relatively thin thickness of the slabs.

\section{Conclusions}

Derived from the results of this analyisis, it seems that it is possible to interrupt the tubes in slab-column concrete-filled tubular connections subjected to compression, since the load is faithfully transferred through the concrete thickness.
Of course this will require further and wider numerical and experimental campaigns, but results from the first numerical analysis that has been carried out show that confinement effect takes place in between the plates, independently of the relative location of the column (corner, façade or central). This confinement effect is the responsible of guaranteeing the transference of compressive load from one tube to other.

However, it is significant to highlight that these connections clearly reduce their capacity when the column is located on the corner, due to the inherent reduction of available area to distribute stress.

\section{References}

[1] Albareda-Valls A, Maristany-Carreras J. Efficiency of stiffening plates in fabricated concrete-filled tubes under monotonic compression. Steel and Composite Structures 2015; 18(4):1023-1044.

[2] Castro Medina JC. Modelización numérica del comportamiento estructural de barras de pandeo restringido. Doctoral Thesis of Polytechnic University of Catalonia 2011; Barcelona. (in Spanish)

[3] Jankowiak T, Lodigowsky T. Identification of parameters of concrete damage plasticity constitutive model. Foundations of Civil and Environmental Engineering 2005; 6:53-69.

[4] Susantha K, Ge H, Usami, T. Uniaxial stressstrain relationship of concrete confined by various shaped steel tubes. Engineering Structures 2000; 23:1331-1347.

[5] Richart FE, Brandtzaeg A, Brown R. A study of failure of concrete under combined compressive stresses. Engineering Experiment Station 1928; Bulletin $\mathrm{n}^{\circ} 185$

[6] Starossek U, Falah N, Löhning T. Numerical analyses of the force transfer in concrete-filled steel tube columns. The 4rth International Conference on Advances in Structural Engineering and Mechanics (ASEM'08) 2008; 2651-2666.

[7] Zhao X, Tong L, Wang X. CFDST stub columns subjected to large deformation axial loading. Engineering Structures 2010; 32:692-703. 